\title{
EVALUATING POTENTIAL FREE SOFTWARE FOR WEB-BASED MULTIMEDIA CARTOGRAPHY
}

\author{
Baqir Abdul Basir, Abdul Rauf Abdul Rasam* \\ Centre of Studies for Surveying Science and Geomatics, Faculty of Architecture, Planning and Surveying, \\ Universiti Teknologi MARA, Shah Alam, Selangor, Malaysia \\ baqirabdulbasir@gmail.com, rauf@uitm.edu.my
}

KEYWORDS: FOSS, Cartography, Web Mapping, Multimedia Cartography, E-Sport

\begin{abstract}
:
Most universities students depend on the use of proprietary software as it has prominent capabilities to meet their needs. Although the proprietary software such as Adobe Flash Professional has a high capability to create a web-based multimedia system, budget constraints become the main reason why free software will be used as an alternative to proprietary software. This study is carried out to evaluate the potential free software for developing a web-based multimedia in cartography projects specifically for students in developing countries. Wix and Weebly are the two software that has been potentially explored among the ten selected software in the market. The current commercial software (Adobe Flash Professional) was also applied as a benchmark to the selected free software. This three software were individually utilised to design and develop a web-based multimedia of e-sport system and their technical capabilities were comparatively assessed according to elements of a common multimedia, website and other mapping assessment aspects. The finding showed that each of the software has unique characteristics and has successfully generated the end products according to the standard web-based multimedia title. Although these free software could produce a better looking, more flexible and time saving mapping platform than the end product created from the Adobe Flash Professional, they have limitation in creating menu function. This exploratory and cases study has also demonstrated that the alternative free software has potentials to replace the current proprietary software, while Wix is the best among the two selected software.
\end{abstract}

\section{INTRODUCTION}

Free Software and Open Source Software (FOSS) is the term that used for program that has a freedom to use, modify and share it legally. Basically, the source code of open source software is available on the internet where skilled developers can refine and modify the program to make it better. Since open source software has open code, more programmers can view the code, create new features and fix bugs. This follows the same natural development as science over time (Yang, 2007). Both have the same meaning but different in views, goals and underlying values. Thus, FOSS is the term that implied as the neutral term for both of the license to avoid confusion (Peterson, 2017).

Adobe Systems develop a proprietary application development platform named Adobe Flash Professional (previously called Macromedia Flash) which once a dominant platform for online multimedia content (Adobe Flash, 2018). It is totally controlled by Adobe and not an open source platform. Flash can show text, raster graphics and vector graphics to produce animations, rich Internet application (RIA), mobile applications, desktop applications, mobile games, embedded web browser video players and what is more, it also allows streaming of video and audio, and the input of mouse, keyboard, microphone, and camera input can be captured.

By using the proprietary software such as Adobe Flash Professional, a multimedia content like web-based multimedia cartography can be developed. A web-based system in multimedia cartography, means integration of mapping in Web as a new form of representation which replace the conventional way of representation of map. The web is an object-oriented environment that enables access to all sorts of (potentially) dynamic, linked object forms featuring geo-information input (including raster images, vector maps, tabular data, text and even sound) (MacEachren, 1998).

Therefore, combination of Web Multimedia, GIS and Cartography has flexible ways of viewing and interacting with geographic information (Black et al., 2015: Hu et al., 2018; Cartwright et al., 2007; MacEachren, 1998). Cartwright et al. (2007) stated concepts of interactive multimedia or hypermedia need to combine with Cartography or geographical information for interactive connecting structure and instinctive manners such as digital world atlas. Fundamental cartographic values and process are still a priority to make an effective map although there are societal and technological transformations (Kraak and Fabrikant, 2017; Steven, 2012). Multimedia cartography also provides an exclusive method to assimilating geospatial information in digital and multimedia information, which is useful for digital socio-humanities integration into geovisualisation due to it deals to the fundamental spatial-based human awareness and knowledge (Hu et al., 2018 and Warf, 2006).

This study starts with a desire to implement the usage of free and open source software for cartography project in Advanced Cartography subject in Universiti Teknologi MARA (UiTM), which will help especially University to gain freedom instead of using proprietary software like Adobe Flash Professional. Not like proprietary software, this free and open source software is less cost which is actually no cost at all in terms of the software but not the hardware. The main purpose of free and open source is the freedom, not the price but in education where expenses become an obstacle, the price is the crucial matter. The problems occur when a University (such as UiTM) must invest a huge amount of money to have the software copyright license for producing web-based multimedia cartography which is included in one of the tasks in cartography project. Thus, this 
study attempts to implement the utilization of free and open source software for web-based multimedia cartography that might help them to reduce cost and at the same time students can gain freedom in usage and distribution.

\section{REVIEW ON FREE AND OPEN SOURCE SOFTWARE FOR CARTOGRAPHY PROJECTS}

\subsection{Free and Open Source Software (FOSS) and Non-Free and Open Source Software}

The software license is an agreement between the software maker and the client, enabling that individual or organization to control the use and redistribute the software. The result of failing to comply with the license agreement can be anything from a fine to a prison sentence. Two common categories of software licensing that will be discussed are free and open source software (FOSS) and proprietary software.

\subsubsection{Definition of FOSS}

FOSS has changed the world of information technology system. FOSS are those the software with the source code (a text listing command in a program where it is formerly written by programmer using a programming language) is publicly available and enable users to freely run the application for any type of purpose, modify the program as they wish and freely distribute copies of the original or modified version. Over recent years, the development of FOSS has growth rapidly because the users have access to the source, so fixing the errors, improving and upgrading the applications is much convenient. Popular FOSS program is easy to discover which covering almost every purpose and task such as office automation (such as Libre Office, Apache OpenOffice), web browsers (such as Chromium, Mozilla Firefox), digital image editor (such as GIMP, Krita), vector graphics editor (such as Inkscape) and much more. Free software is also widely used for GIS and cartography (Zaragozí et al., 2012).

The two common terms 'free software' and 'open source software' has a different rule and meaning. Free Software Foundation (FSF) defines the term free software as the software that allows user the freedom to run, copy, distribute, study, change, and modify the software. Free software must satisfy four essential freedoms to consider as free software;

a. The freedom to run the software for any intention without restrictions.

b. The freedom to analyse how the software works and modify it according to your needs.

c. The freedom to distribute program to others who need helps.

d. The freedom to share out modified version copies of program to others.

Both terms have different philosophy and ideas although their root words have the closest meaning (right to use, study, distribute, and modify). Bear in mind that, not all open source software is free software and all free software is open source software (Chew, 2018; Garbade, 2018; Peterson, 2017; Sood, 2017; Terbuc, 2007). Open source is a development philosophy where it is more specific to business-oriented while free software is a community or social movement philosophy where freedom is what matter. In order to minimize misunderstandings of terms debate between free software and open source software, the terms such as FOSS can be apply to portray the concepts (Garbade, 2018).

\subsection{FOSS in Geomatics and Cartography}

Geomatics field of study consist of several specialized fields including Geographic Information System (GIS), photogrammetry, remote sensing, Cartography and other scientific geospatial-based studies. Software application is very crucial in the process of obtaining, analyse, calculation, visualize, process and management of data as conducted by previous studies in environmental applications (Zaragozí. 2012; Jamaluddin et al., 2018; Abdul Rasam et al., 2014). Software developer developed a lot of software to meet the needs of users either proprietary or free and open source application and users are free to choose if they meet the requirements of their work. The implementation of FOSS in Geomatics field is growing rapidly in some developed countries where government are towards the development of FOSS as they are releasing their data for free. Government efforts towards implementing FOSS bring a huge advantage especially in education sector. While costs issue is the main issue in the use of Information Communication and Technology (ICT) in education, barriers to the access of ICT can be lowered by using FOSS as the cost of software is reduced (Terbuc, 2007). Technological advancement and the use of education technology especially in higher education is growing rapidly, making free and open source software more relevant to implement in the institution to reduce costs (Blake \& Morse, 2016).

\subsection{Usefulness of FOSS in Cartography Projects}

One of main subject in a geomatic department worldwide is Advanced Cartography where students were basically assigned to undertake a project. In the project, one of the tasks is to create web-based multimedia mapping by using Adobe Flash Professional or other mapping software. Usage of proprietary software like Adobe Flash Professional in Cartography project is only used for a single subject in a single semester. In contrast with other proprietary software like ArcGIS where it is been used by numerous subjects and every semester in the geomatic department such as in UiTM. With the implementation of FOSS either free software or free and open source software in cartography project, it will reduce the cost rather than spending a huge amount of money for renewing the software license during at the end of subscription period. Aside from cost benefits, FOSS also has another benefit in terms of reliability, extendibility and security.

\section{DATA AND METHODS}

A standard of multimedia titles used for creating the web-based multimedia cartography in this study. The titles include system planning and study, system implement and designing, and lastly system testing and evaluation.

\subsection{Phase of Planning and Study}

A research and findings have been run to examine the capabilities and availability of the free and open source software in the market to build a web-based multimedia cartography. During this phase, each of the free and open sources software has been explore and review by doing research on internet, journal and explore its capabilities to create multimedia mapping which is comparable with proprietary software. This method is one of the efficient ways to start this planning phase. By doing this method, the highly recommended software can be selected to be an alternative to proprietary software. 


\subsubsection{Selection of Software for Web-Based Multimedia Cartography Project (E-Sports System)}

The selection of free and open source software for creating a web-based multimedia cartography project is very crucial in making this study meet the targeted end results. When selecting the best software for a web-based multimedia cartography project, the requirement of the software that involve the element of map making in cartography need to be considered in order to ensure this project fulfil the necessity. All the software that has been found is licensing either as free software or free and open source software. Wix and Weebly are the two software that has been potentially explored in this study.

\subsubsection{Using Wix}

Wix is selected as the best software for a web-based multimedia cartography project. Wix is a free web-based application and it is works for all type of Operating System. Supported browsers for desktop and mobile devices:

a. Google Chrome.

b. Safari for Mac (version 10 and above).

c. Windows 10 Microsoft Edge (ADI sites are not supported).

d. Firefox.

e. Google Chrome (mobile app).

f. Safari (iPhone 6 and above).

Wix does not support in-app browsers. For example, when click a link inside the Facebook mobile app. Wix Website Editor, the place to edit the site must be using computer and it is not possible to edit the site using touchscreen devices including mobiles and tablets.

\subsubsection{Using Weebly}

Weebly is selected as the second suitable software for a webbased multimedia cartography project. Weebly is same as Wix, a free web-based application and it is works for all type of Operating System. Latest version of any mainstream web browser such as Internet Explorer, Safari, Firefox, or Chrome is suitable to run Weebly.

\subsection{Phase of Implementation, Creating and Designing}

In this phase, the first step that needs to do is to implement the free and open source software to create web-based multimedia cartography. The selected software was implemented using cartography group project which is multimedia mapping of esports training facilities. This phase created a product of webbased multimedia mapping for e-sports training facilities.

\subsubsection{Design and Development of a Web-Based Multimedia Cartography Project}

This project was influenced by e-sports in Malaysia that have growing rapidly. Skills and knowledge in e-sports must be developed by training regularly to be a professional player. A good training facility play an important role in develops skills in e-sports game. With this project, it will provide a guide for those who want to expend their talent in e-sports game.

The aim and main objective are to provide a web-based multimedia map of e-sports training facilities that available in Selangor that will guide rookie gamers as well as professional gamers to enhance their skills. This map shows the name, rating and type of game of selected e-sports training facilities that available in Selangor. This map was created to be a perfect guideline for both rookie and professional player to find the best and suitable e-sports training facilities that suits their needs

\subsubsection{Concept of Design}

Concept of design in web-based multimedia cartography consists of three process which are information design, interaction design and presentation design. Information design defines the product and audience, plan the project, organize the content into flow chart while interaction design defines the design the navigation, types of interaction, and controls, maps all these into storyboard and for presentation design, it defines the style and layout of the elements in the storyboard and produce a prototype.

\subsubsection{Information Design}

First process in web-based multimedia cartography is information design where it is considered to define the goal of the product and what the audience wants to do. The way how the product will reach its audience is very important. A proper process in information design phase will bring in the audience satisfaction. The audience needs and what the element that should include in design are listed below:

a. Learn - Clarity, simplicity, repetition, reinforcements, breakdown into short presentation, testing, remedies.

b. Have fun - Variety, surprises, randomness, wit, unpredictable events each time product is used.

c. Understand - Conceptual explanations such as "how it works", illustrations, video.

d. Experience - High level of interactivity, user control actions, events, realistic sights, sounds.

e. Act or buy - Well-defined features and benefits, options, toll-free number, interactive order forms.

f. Get answers - Reference style organizations, fast access, searchable index of contents.

Then, the project was planned carefully by thinking through all the implications, time, cost and many more things that should be taken account followed by the organization of the project content into a flow chart. A clear and easy flow chart indicates the shape and structure of the project so that audience can get a sense how the real product will work.

\subsubsection{Interaction Design}

Second process in web-based multimedia cartography is interaction design where it is focused on the mechanics of the design and this process is the answer to how it is works question. How the user controls the sequence, the pace and most crucially is what to look and what to ignore are the purpose of interactivity elements. Thus, it solved what the users want to do and a user telling computer what to do is the basis of all interaction design.

The storyboard was designed during this process. Storyboard is a living document that is modified and updated as the design continues. The storyboard is blocked as a series of thumbnail sketches. The objective is to integrate content with controls, working with real screens and make necessary decisions about functionality. The completed storyboard is declared as blueprint for all design activities, creating the graphics and media that make up every screen. 


\subsubsection{Presentation Design}

Third process in web-based multimedia cartography is presentation design, a style, composition and layout of the elements on the screen that make up as an interface. It is performed as a visual language to make the elements alive, work together and support the functions on each screen. The starting point of presentation design is the storyboard that acts as a conceptual structure. The task that was accomplished during this process is:

a. Defining the visual theme and style.

b. Designing a system of screen layouts.

c. Creating a structural element of each screen (backgrounds, windows etc.).

d. Creating the control elements (buttons etc.).

e. Integrating the media elements (images etc.).

f. Creating a prototype screen.

Everything in this product in form of digital media such as text, pictures, video and sounds need to be converted to digital format. An image and sound are in high quality, and able to run on most computer where the performance or the speed of display, the amount of memory and disk space needs. The factors to be considered in this process is resolution of the screen, colour and colour palette, compression of images and video and conversion of images, videos and sound to digital formats.

The resolutions of project influence the design of web-based multimedia. A nice and suitable colour plays an important role in this project. Colour depth determines whether the design can contain just a few hundred colours or a few million, means the number of bits of information used to describe each pixel in an image. When deal with designing for screen, compression is considered so it can be stored, processed and moved around the computer fast enough to produce good interactive performance.

The interface must include background, button and menu styles navigation options are shared and repeated among screens. Background provides the location and context for all the action on the stage. The layout of interface must be arranged to consider it as good looking and understand to use. Layout contains object such as structural object like windows and borders, informational object like words and pictures and functional object like buttons and controls.

The text is used to create words, sentences and paragraphs. With this text, it is good at providing basic information and information of the project. Insufficient attention given to the presentation and flow of text within this project can result in the failure to communicate the presentation's central message. Image is another crucial element in presentation design. There are two kinds of images in this project, standalone image which is photo and component images which is a map with buildings composed into an information montage.

\subsection{Phase of Testing and Evaluation}

\subsubsection{Comparative Studies of Free Software Capabilities for} Developing a Web-Based Multimedia Cartography Project

In this phase, the implementation, testing and distribution were implemented. This phase is the process to evaluate the capabilities of the selected free and open source software. The selected software is evaluated based on the following aspects:

a. Application type.

b. License. c. Map.

d. Navigation.

e. Digital graphic.

f. Flexibility.

g. Elements of multimedia.

h. Elements of web-based system.

The suitable and recommended free and open source software that have been choose could be used by geomatic departments as an alternative to the current proprietary software which is Adobe Flash Professional and ArcGIS Online.

\section{RESULT AND DISCUSSION}

\subsection{Selection of Open Source Software}

There are 10 FOSS were selected that available in the market and internet which are Wix, Weebly, Joomla! Google Sites, WordPress, Vectorian Giotto, Synfig Studio, Wick Editor, OpenToonz and NanoFL. All the software are listed as the alternative to the current software which is Adobe Flash Professional. Table 4.1 shows the list of all the software and the details alongside with authors' comments for each of the software.

Table 4.1 List of software

\begin{tabular}{|c|c|c|c|}
\hline Software & License & Detail & Comments \\
\hline Wix & Free & $\begin{array}{l}\text { - Website builder } \\
\text { - Web-based } \\
\text { application }\end{array}$ & $\begin{array}{l}\text { Drag and drop feature } \\
\text { User-friendly } \\
\text { Versatility and flexible } \\
\text { Stunning template } \\
\text { Mobile optimized } \\
\text { Can use free domain and } \\
\text { web hosting } \\
\text { Can fulfil all requirement } \\
\text { to create web-based } \\
\text { multimedia cartography }\end{array}$ \\
\hline Weebly & Free & $\begin{array}{l}\text { - Website builder } \\
\text { - Web-based } \\
\text { application }\end{array}$ & $\begin{array}{l}\text { Drag and drop feature } \\
\text { User-friendly } \\
\text { Less flexible than Wix } \\
\text { Decent template } \\
\text { Mobile optimized } \\
\text { Can use free domain and } \\
\text { web hosting } \\
\text { Can fulfil all requirement } \\
\text { to create web-based } \\
\text { multimedia cartography }\end{array}$ \\
\hline Joomla! & $\begin{array}{l}\text { Free } \\
\text { and } \\
\text { Open } \\
\text { Source }\end{array}$ & \begin{tabular}{|l} 
Content \\
Management \\
System \\
- Web-based \\
application
\end{tabular} & $\begin{array}{l}\text { Less flexible than } \\
\text { Wordpress } \\
\text { Not user-friendly } \\
\text { Need to have domain } \\
\text { and hosting first }\end{array}$ \\
\hline $\begin{array}{l}\text { WordPre } \\
\text { ss }\end{array}$ & $\begin{array}{l}\text { Free } \\
\text { and } \\
\text { Open } \\
\text { Source }\end{array}$ & $\begin{array}{l}\text { Content } \\
\text { Management } \\
\text { System } \\
\text { - Web-based } \\
\text { application }\end{array}$ & $\begin{array}{l}\text { Flexible } \\
\text { Not user-friendly } \\
\text { Need to have domain } \\
\text { and hosting first }\end{array}$ \\
\hline $\begin{array}{l}\text { Google } \\
\text { Sites }\end{array}$ & Free & $\begin{array}{l}\text { - Website builder } \\
\text { - Web-based } \\
\text { application }\end{array}$ & $\begin{array}{l}\text { Google Apps integrated } \\
\text { Limited theme, template } \\
\text { and design } \\
\text { Too simple and lack of } \\
\text { features like Wix and } \\
\text { Weebly }\end{array}$ \\
\hline $\begin{array}{l}\text { Vectorian } \\
\text { Giotto }\end{array}$ & Free & $\begin{array}{l}\text { - Flash animation } \\
\text { software } \\
\text { - Desktop-based } \\
\text { application }\end{array}$ & $\begin{array}{l}\text { Discontinued } \\
\text { Similar software like } \\
\text { Adobe } \\
\text { Professional but the } \\
\text { software crash regularly. }\end{array}$ \\
\hline $\begin{array}{l}\text { Synfig } \\
\text { Studio }\end{array}$ & $\begin{array}{l}\text { Free } \\
\text { and }\end{array}$ & $\begin{array}{l}\text { - Flash animation } \\
\text { software }\end{array}$ & $\begin{array}{c}\text { Features and tools are } \\
\text { suitable }\end{array}$ \\
\hline
\end{tabular}




\begin{tabular}{|c|c|c|c|}
\hline & $\begin{array}{l}\text { Open } \\
\text { Source }\end{array}$ & $\begin{array}{l}\text { Desktop-based } \\
\text { application }\end{array}$ & cartoon/animation artist \\
\hline $\begin{array}{l}\text { Wick } \\
\text { Editor }\end{array}$ & $\begin{array}{l}\text { Free } \\
\text { and } \\
\text { Open } \\
\text { Source }\end{array}$ & $\begin{array}{l}\text { - Flash animation } \\
\text { software } \\
\text { - Web-based } \\
\text { application }\end{array}$ & $\begin{array}{l}\text { - Features and tools are } \\
\text { suitable for beginner } \\
\text { cartoon/animation artist }\end{array}$ \\
\hline $\begin{array}{l}\text { OpenToo } \\
\text { nz }\end{array}$ & $\begin{array}{l}\text { Free } \\
\text { and } \\
\text { Open } \\
\text { Source }\end{array}$ & $\begin{array}{l}\text { - Flash animation } \\
\text { software } \\
\text { - Desktop-based } \\
\text { application } \\
\end{array}$ & $\begin{array}{l}\text { - Features and tools are } \\
\text { suitable } \\
\text { cartoon/animation artist }\end{array}$ \\
\hline NanoFL & Free & $\begin{array}{l}\text { - Flash animation } \\
\text { software } \\
\text { - Desktop-based } \\
\text { application } \\
\end{array}$ & $\begin{array}{l}\text { Discontinued } \\
\text { The software installer is } \\
\text { unavailable }\end{array}$ \\
\hline
\end{tabular}

\subsection{System Design of Web-Based Multimedia Cartography}

The web-based multimedia cartography system was created and designed by using the selected software. The first software is by using Wix, a web-based application and the second software is by using Weebly which have the similarity with Wix. Adobe Flash was also used to create the system. Result and discussion about the web-based system capabilities are as follow:

\subsubsection{Wix}

The web-based multimedia cartography that was created using Wix consist of 5 sections which are home, about, location, gallery and contact as shown in Figure 1.

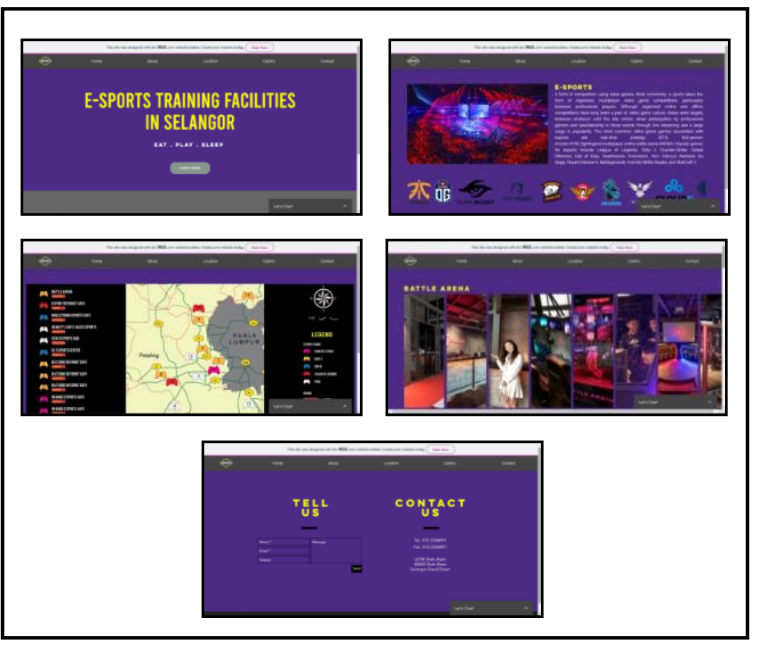

Figure 1. E-sports system created by using Wix

Home page act as the introduction of the web-based multimedia cartography system. There are five buttons available in the top of the interface where each of them has the purpose to meet the needs of users who access this system such as home, about, location, gallery and contact. The bottom section of the page in this system has link that navigate directly to the social media platform such as Instagram, Twitter, Facebook and so on.

About page was designed to provide brief information about the history of e-sports, example of e-sports game that commonly played in the world and the best e-sports team in the world. Next, this section can be access from the shortcut button that placed in the main page. The thematic map of e-sports system located in Location page. The thematic map includes the best esports training facilities in Selangor with the ratings and type of game provided. It also includes the basic features of map such as legend, north arrow, scale and grid. Users also can view the address in Google Maps of the e-sports training facilities by clicking on the hyperlink on the e-sports facilities name.
Gallery page shows a variety of picture from all the e-sports training facilities that were listed in this web-based multimedia cartography system. Users can view the pictures that illustrating what equipment available and the conditions of the place at the e-sports training facilities. Contact page created to directly communicated and gain user opinion or feedback. All feedback or comments will be submitted to the database and will be analyse before taking any actions.

\subsubsection{Weebly}

The web-based multimedia cartography that was created using Weebly consist of 5 sections which are home, about, location, gallery and contact as illustrated in Figure 2.

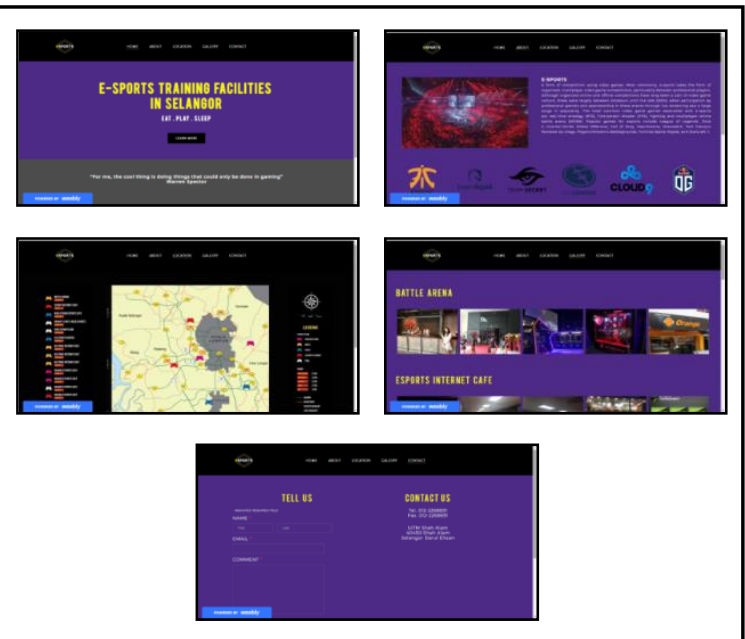

Figure 2. E-sports system created by using Weebly

Main page act as the introduction of the web-based multimedia cartography system. There are five buttons available in the top of the interface where each of them has the purpose to navigate users to access such as home, about, location, contact and gallery. Each of the bottoms section of the page in this system has link that navigate directly to the social media platform as same as the web-based multimedia cartography that was created by using Wix.

About page was created to provide brief information about the history of e-sports, example of e-sports game that commonly played in the world and the best e-sports team in the world. Next, this section can be access from the shortcut button that placed in the main page. The thematic map of e-sports system located in Location page. The thematic map includes the best esports training facilities in Selangor with the ratings and type of game provided. It also includes the basic features of map such as legend, north arrow, scale and grid. However, users do not have features to view the address of the e-sports training facilities as same as the system that created in Wix. It is because an element (hyperlink) would not be able to stack on top of other element which make it impossible to link address when clicking the name of the e-sports training facilities.

Gallery page shows a variety of picture from all the e-sports training facilities that were listed in this multimedia cartography system. Users can view the pictures that illustrating what equipment available and the conditions of the place at the esports training facilities. Contact page created to directly communicated and gain user opinion or feedback. All feedback 
or comments will be submitted to the database and will be analyse before taking any actions.

\subsubsection{Adobe Flash Professional}

The web-based multimedia cartography that was created using Wix consist of 5 sections which are home, about, location, gallery and contact as shown in Figure 3.

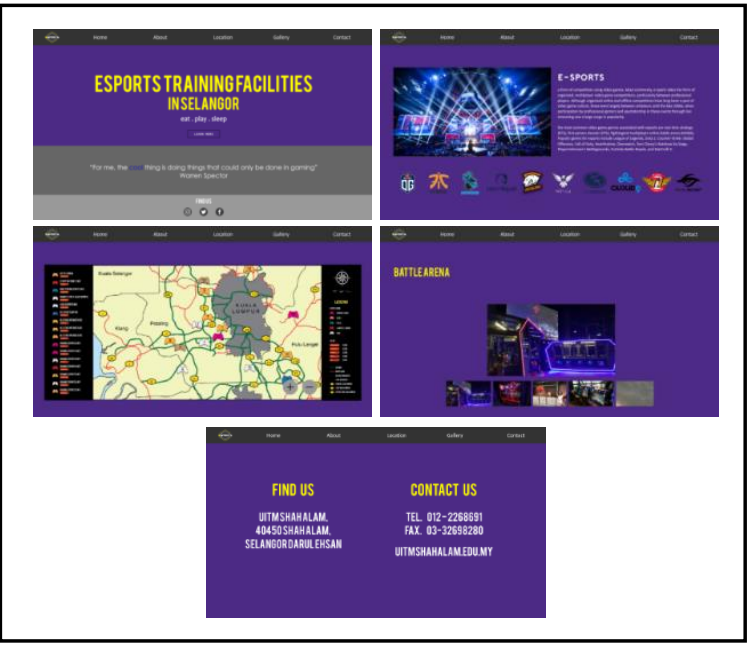

Figure 3. E-sports system created by using Adobe Flash Professional

Main page of the web-based multimedia cartography is act as the introduction of the system. There are five buttons available in the top of the interface where each of them has the purpose to navigate users to access such as home, about, location, contact and gallery. The bottom section of the page in this system has link that navigate directly to the social media platform such as Instagram, Twitter, Facebook and so on.

About page was created to provide brief information about the history of e-sports, example of e-sports game that commonly played in the world and the best e-sports team in the world. Next, this page can be access from the shortcut button that placed in the main page. The thematic map of e-sports system located in Location page which include the best e-sports training facilities in Selangor with the ratings and type of game provided. There is zoom in and zoom out button function that created in order to enlarge or reduce the view of the thematic map. Users can also use pan navigation in the thematic map.

Gallery page shows a variety of picture from all the e-sports training facilities that were listed in this multimedia cartography system. Users can view the pictures by clicking the picture one by one. Contact page was created to directly communicated and gain user opinion or feedback.

\subsubsection{Design and Develop the System Using Wix, Weebly and Adobe Flash Professional}

All software has same capabilities in term of our design based on the storyboard, but the difference is Wix and Adobe Flash Professional can use a wide variety of fonts that available in the internet compared to Weebly which has limited number of fonts. In Wix, user can move and drag items freely as same as in Adobe Flash Professional while Weebly can only move to their given spacing. Moreover, in Adobe Flash Professional, users need to write a very complicated ActionScript programming language in order to create a picture gallery. The tutorial for the ActionScript that available in the internet is also limited but in
Wix and Weebly, it can easily create any type of picture gallery without coding and has a variety of type to choose from.

\subsection{Comparative Analysis between Wix, Weebly and Adobe Flash Professional for Multimedia Cartography system}

From the design and analysis using Wix, Weebly and Adobe Flash Professional, it can be concluding that each software has their own capabilities for multimedia cartography system. Table 2 shows the software assessment aspects of three software which are Wix, Weebly and Adobe Flash Professional.

Table 2. Software assessment aspects for web-based multimedia Cartography

\begin{tabular}{|c|c|c|c|c|}
\hline \multicolumn{2}{|c|}{ Assessment aspects } & Wix & Weebly & Flash Pro \\
\hline \multirow{2}{*}{$\begin{array}{l}\text { Application } \\
\text { type }\end{array}$} & Desktop-based & $x$ & $x$ & $\checkmark$ \\
\hline & Web-based & $\checkmark$ & $\checkmark$ & $x$ \\
\hline License & Free and open source & $\checkmark$ & $\checkmark$ & $x$ \\
\hline Map & Interactive map & $\checkmark$ & $\checkmark$ & $\checkmark$ \\
\hline \multirow{3}{*}{ Navigation } & Zoom & $\checkmark$ & $\checkmark$ & $\checkmark$ \\
\hline & Pan & $\checkmark$ & $\checkmark$ & $\checkmark$ \\
\hline & Hyperlink & $\checkmark$ & $\checkmark$ & $\checkmark$ \\
\hline \multirow{2}{*}{$\begin{array}{l}\text { Digital } \\
\text { graphic }\end{array}$} & Vector graphic & $\checkmark$ & $\checkmark$ & $\checkmark$ \\
\hline & Raster graphic & $\checkmark$ & $\checkmark$ & $\checkmark$ \\
\hline \multirow{2}{*}{ Flexibility } & Coding & $x$ & $x$ & $\checkmark$ \\
\hline & Drag and drop & $\checkmark$ & $\checkmark$ & $x$ \\
\hline \multirow{5}{*}{$\begin{array}{l}\text { Elements } \\
\text { of } \\
\text { multimedia }\end{array}$} & Text & $\checkmark$ & $\checkmark$ & $\checkmark$ \\
\hline & Image & $\checkmark$ & $\checkmark$ & $\checkmark$ \\
\hline & Audio & $\checkmark$ & $\checkmark$ & $\checkmark$ \\
\hline & Video & $\checkmark$ & $\checkmark$ & $\checkmark$ \\
\hline & Animation & $\checkmark$ & $\checkmark$ & $\checkmark$ \\
\hline \multirow{5}{*}{$\begin{array}{l}\text { Elements } \\
\text { of web- } \\
\text { based }\end{array}$} & Mobile compatibility & $\checkmark$ & $\checkmark$ & $x$ \\
\hline & Accessible (internet) & $\checkmark$ & $\checkmark$ & $x$ \\
\hline & Error handling & $\checkmark$ & $\checkmark$ & $\checkmark$ \\
\hline & $\begin{array}{l}\text { Well-formatted } \\
\text { content }\end{array}$ & $\checkmark$ & $x$ & $\checkmark$ \\
\hline & Colour scheme & $\checkmark$ & $\checkmark$ & $\checkmark$ \\
\hline
\end{tabular}

Based on the result on the Table 2, all three software is evaluated for designing multimedia cartography by using cartography project (e-sports system). Wix, Weebly and Adobe Flash Professional can be used to create multimedia cartography because it can create all elements of multimedia which is text, image, audio, video and animation. Wix and Weebly are webbased applications while Adobe Flash Professional is a desktopbased application. This makes Wix and Weebly do not have installability features because users are free to use and access by only using a web browser compared to Adobe Flash Professional where users have to install the software on the computer only after the user purchased it.

Wix and Weebly is very user-friendly make it them learnability compared to Adobe Flash Professional where user have to take a certain course and tutorial, for example ActionScript tutorial, in order to understanding the tools and functions. Besides the elements of multimedia, the elements of web-based such as mobile compatibility, accessible, error handling, well-formatted content and colour scheme are available in Wix which makes a good alternative to Adobe Flash Professional except Weebly which only do not has well-formatted content element. Other than that, Wix and Weebly also provide interactive map features as well as navigation feature like zoom, pan and hyperlink. 
Vector and raster graphics can also work in both software which are comparable with Adobe Flash Professional.

\section{CONCLUSIONS}

The implementation of free software is the best alternative to the proprietary software in accomplishing user's task. Most of universities students are depending on proprietary software as it has the capabilities to meet their needs and requirements. For example, geomatic students in UiTM were generally taught to use proprietary software like Adobe Flash Professional for creating a web-based multimedia cartography. However, cost constraint and complicated user interface are two possible longterm main issues are identified in this study. The question is that any alternative free software potentially replaces the current proprietary software for developing a web-based multimedia cartography? Wix and Weebly were explored in this study to design the web-based multimedia elements of e-sports system in Selangor. The free software successfully generated the products that has a better looking, more flexible and time saving than the end products from the Adobe Flash Professional. The result of the evaluation has been analysed and it clearly shows that the alternative free software can potentially replace the current proprietary software for developing a web-based multimedia cartography especially in UiTM. Wix is the best among the two selected software and Weebly is the second alternative after Wix Although free software has potential functions as posed by proprietary software, this study also needs to take into account academic and industrial perspectives to produce flexible and dynamic graduates

\section{ACKNOWLEDGEMENTS}

A special thanks to Centre of Studies for Surveying Science and Geomatics (PPSUG), Faculty of Architecture, Planning and Surveying UiTM Selangor that contribute during this research was conducted. Great thanks also to the respondents for their contributions and cooperation to this study, especially those who participated in software evaluation during the UiTM Cartography Project Competition June 2019.

\section{REFERENCES}

Adobe Flash. (2018). In Wikipedia. Retrieved November 15, 2018, from https://en.wikipedia.org/wiki/Adobe_Flash

Abdul Rasam, A.R., Wahab, N. A. A., Ghazali R., Yusoff, Z.M., 2014: Integrating open source GIS and Google Earth ${ }^{\mathrm{TM}}$ for managing rural waterborne outbreaks, 2014 IEEE 10th International Colloquium on Signal Processing and its Applications, Kuala Lumpur, 2014, 62-66.doi: 10.1109/CSPA.2014.6805721

Black, M. A., Cartwright, W. E., 2005: Web cartography and webenabled Geographic Information Systems (GIS): new possibilities, new challenges. Proceedings of the 22nd International Geographic Conference., 1-10.

Blake, M. R., Morse, C., 2016: Keeping your options open: A review of open source and free technologies for instructional use in higher education. Reference Services Review., 44(3), 375-389. https://doi.org/10.1108/RSR-05-2016-0033
Cartwright, W., Gartner, G., Peterson, M. P, 2007. Multimedia Cartography. Multimedia Cartography: Second Edition. https://doi.org/10.1007/978-3-540-36651-5

Chew, J, 2018. OpenToonz Review. Retrieved May 29, 2019, from https://www.lifewire.com/opentoonz-review-4018840

Garbade, M. (2018). Free Software vs Open Source vs Freeware: What's the Difference? Retrieved May 29, 2019, from https://dzone.com/articles/free-software-vs-open-source-vsfreeware-whats-the

Hu, S., Karna, B., Hildebrandt, K., 2018: Web-based Multimedia Mapping for Spatial Analysis and Visualization in the Digital Humanities: A Case Study of Language Documentation in Nepal. Journal of Geovisualization and Spatial Analysis., 2(1), 3. https://doi.org/10.1007/s41651-017-0012-4

Kraak, M.-J., Fabrikant, S. I., 2017: Off Maps, cartography and the geography of the International Cartographic Association. International Journal of Cartography., O(0), 1-23. https://doi.org/10.1080/23729333.2017.1288535

Kraak, M.-J. (2001). Classification of web maps. In Web cartography: developments and prospects (Settings and needs for web cartography). Retrieved November 14, 2018, from http://kartoweb.itc.nl/webcartography/webmaps/dynamic/dynamic. $\mathrm{htm}$

Jamaluddin, A.S., Abdul Rasam, A.R., Khalid, N., Halim, M. A., 2018: Exploring Open Source GIS for Drug Mapping and Analysis in Malaysia,2018 IEEE 8th International Conference on System Engineering and Technology (ICSET), Bandung, 2018, 91-96.doi: 10.1109/ICSEngT.2018.8606360

MacEachren, A. M., 1998: Cartography, GIS, and the World Wide Web. Progress in Human Geography., 22(4), 575-585. https://doi.org/10.1145/228228.228235

Peterson, S. K, 2017. What's the difference between open source software and free software? Retrieved May 29, 2019, from https://opensource.com/article/17/11/open-source-or-free-software

Sood, G., Shipra, Soni, R., 2016. Comparative Study: Proprietary Software vs. Open Source Software. International Journal of Innovative Research in Computer and Communication Engineering., $4(11), \quad 19032-19038$. https://doi.org/10.15680/IJIRCCE.2016.

Stevens, J., Smith, J. M., Bianchetti, R. A., 2012: The Cartographic Process. Retrieved November 15, 2018, from https://www.eeducation.psu.edu/geog160/node/1882

Terbuc, M., 2007: Use of free/open source software in e-education. EPE-PEMC 2006: 12th International Power Electronics and Motion Control Conference, Proceedings, (June), 1737-1742. https://doi.org/10.1109/EPEPEMC.2006.283109

Warf, B, 2006. Cartography. https://doi.org/10.1007/978-1-40204411-3

Web Based Application. 2007. In Netsity. Retrieved November 14, 2018, from http://www.netsity.com/webbasedapplication.htm Yang, C. N. (2007). Taoism of open source. Retrieved May 29, 2019, from https://www.linux.com/news/taoism-open-source

Zaragozí, B., Giménez, P., Navarro, J. T., Dong, P., \& Ramón, A. (2012). Development of free and opensource GIS software for cartographic generalisation and occupancy area calculations. Ecological Informatics, $\quad 8, \quad 48-54$. https://doi.org/10.1016/j.ecoinf.2012.01.002 